\title{
The effects of beetroot containing bread on arterial stiffness and other risk factors for cardiovascular disease
}

\author{
D. A. Hobbs ${ }^{1,2}$, T. W. George $\mathrm{e}^{1,2}$, L. Methven ${ }^{1}$ and J. A. Lovegrove $\mathrm{C}^{1,2}$ \\ ${ }^{1}$ Department of Food and Nutritional Sciences and ${ }^{2}$ Institute for Cardiovascular and Metabolic Research (ICMR), \\ University of Reading, Whiteknights, PO Box 226, Reading, Berks, RG6 6AP, UK
}

Despite initiatives to increase consumption, current fruit and vegetable intake is below recommendations ${ }^{(1)}$. Novel interventions to increase consumption are therefore of considerable interest. Cardio-protective effects of beetroot have been attributed to its high nitrate content $^{(2)}$. Following ingestion, nitrate is reduced to nitrite by oral bacteria, and further to vasodilator nitric oxide (NOx) endogenously ${ }^{(3)}$. To test the hypothesis that nitrate-rich beetroot containing bread improves arterial stiffness and other risk factors for cardiovascular disease (CVD) a single-blind, randomised, controlled crossover, postprandial study was performed in twenty-four healthy men (mean age 32 (SD 9) years and body mass index 23.3 (SD 2) $\mathrm{kg} / \mathrm{m}^{2}$ ).

Participants consumed $200 \mathrm{~g}$ of bread containing $100 \mathrm{~g}$ of beetroot $(1.1 \mathrm{mM}$ nitrate) or control bread (no beetroot, $<0.8 \mathrm{mM}$ nitrate) in a random order separated by 2 weeks. Arterial stiffness using pulse wave analysis (PWA) was measured at baseline and at 2 hourly intervals for a period of 6 hours. Blood and urine samples were taken at baseline and at regular intervals throughout the study day and were subsequently analysed for lipids, glucose, insulin, potassium, nitrate and nitrite. The participants followed a low nitrate and nitrite diet and no vigorous activity for 48 hours prior to and during the study day. A low nitrate and nitrite standard meal was provided for the evening before the study day.

Significantly lower area under the curve (AUC) for arterial stiffness (Fig. a; $P=0.018$ ) was observed for 4 hours after beetroot bread consumption, compared to control. There was a significant time by treatment interaction for plasma nitrite $(P=0.0001)$ and nitrate $($ Fig. b; $P=0.0001)$ for 7 hours and urinary nitrite for 4 hours after beetroot bread ingestion compared to control. Urinary nitrate was higher after beetroot bread consumption compared to control, but did not quite reach significance $(P=0.06)$. There were no significant differences in non-esterified fatty acids, triacylglycerol, potassium, glucose or insulin between the two treatments.

(a)

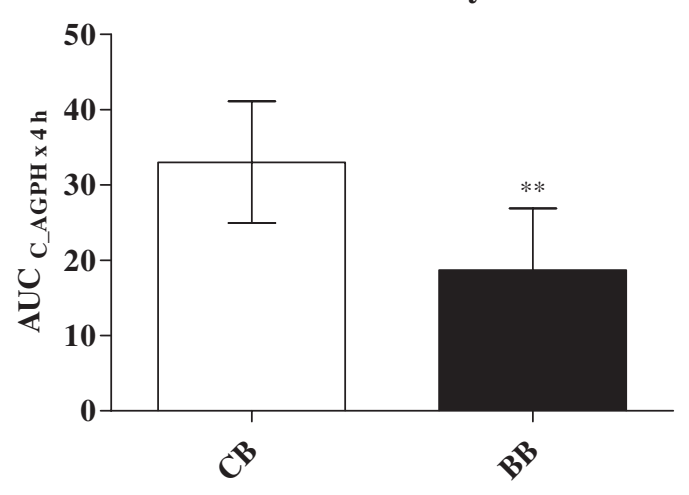

(b)

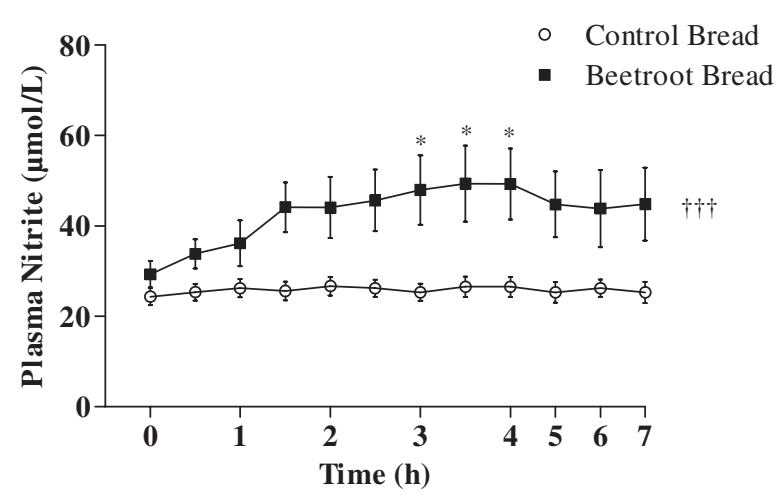

Figure 1: (a) The mean AUC for PWA (C_AHPH) from baseline to 4 hours ( $* *=p<0.01 v s$. control) and (b) mean plasma nitrate concentration at baseline and up to 7 hours after consumption of control bread, CB (no beetroot) beetroot containing bread BB $(*=p<0.0001 v s$. control) (mean \pm SE). Significance shown as ANOVA $† \dagger \dagger P=0.0001$ beetroot bread $v s$. control followed by bonferroni post test for beetroot bread $v s$. control $* P=0.05$.

In summary, acute consumption of beetroot containing bread improved arterial stiffness, which occurred in association with an increase in plasma and urinary nitrate and nitrite. Beetroot containing bread may serve as a potential vehicle to increase consumption of cardioprotective beetroot in the diet.

1. Department of Health (2011) National Diet and Nutrition Survey.

2. Webb AJ, Patel N, Loukogeorgakis S et al. (2008) Hypertension 51, 784-90.

3. Kapil V, Milsom AB, Okorie M et al. (2010) Hypertension 56, 274-81. 